\title{
Investigation of natural ventilation performance of large space circular coal storage dome
}

\begin{abstract}
:
Large space circular coal storage dome (LSCCSD) offers an environmental and dependable alternative to open stockpiles, and it has been consequently widely applied in China. However, due to the lack of scientific guidelines, its natural ventilation performance is lower than expected. Natural ventilation potential strongly depends on the roof geometry and opening mode, which have not yet been investigated for LSCCSD. This paper presents a detailed evaluation of the impact of dome geometry, i.e., rise span ratio, and opening modes on the ventilation performance of LSCCSD. The evaluation is based on computational fluid dynamics (CFD) methods and is validated by available wind tunnel testing. We employed three evaluation indicators, which are wind pressure coefficient, effective ventilation rate, and wind speed ratio. The results demonstrate that the rise span ratio has a significant effect on the wind pressure difference and ventilation flow, and the annular opening should be set in a strong positive pressure zone. For cases of a single-annular opening, the effective ventilation rate increases by $9 \%-42 \%$. For cases of double-annular openings, the effective ventilation rate increases by $100 \%$ and average wind speed ratio increases by $50 \%$ compared with that of a single one. The optimum natural ventilation performance for LSCCSD is achieved at a rise span ratio of 0.37 . In addition, the lateral middle opening is kept higher than the ridge top of the coal pile. The proposed evaluation approach and design parameters provided instructive information in the building design and ventilation control for LSCCSDs.
\end{abstract}


Keywords: Large space circular coal storage dome; Natural ventilation performance;

Opening mode; Computational fluid dynamics (CFD); Evaluation indicator

\begin{tabular}{|c|c|c|c|}
\hline \multicolumn{4}{|c|}{ List of symbols } \\
\hline CFD & Computational fluid dynamics & RNG & Renormalization Group \\
\hline LSCCSD & $\begin{array}{l}\text { Large space circular coal storage } \\
\text { dome }\end{array}$ & $U$ & Wind velocity at the selected point \\
\hline$B$ & Opening height & UDF & User-defined function \\
\hline$C_{p}$ & Wind pressure coefficient & $U_{\text {ref }}$ & $\begin{array}{l}\text { Average wind speed at the upstream } \\
\text { reference height }\end{array}$ \\
\hline$C_{p s}$ & $\begin{array}{l}\text { Surface-averaged wind pressure } \\
\text { coefficient }\end{array}$ & $w$ & Dome cornice width \\
\hline$C_{p s, \text { in }}$ & $\begin{array}{c}\text { Surface-averaged } C_{p} \text { of the inlet } \\
\text { surface }\end{array}$ & Y & Reference height \\
\hline$C_{p s, \text { out }}$ & $\begin{array}{c}\text { Surface-averaged } C_{p} \text { of the outlet } \\
\text { surface }\end{array}$ & $\Delta C_{p s}$ & $\begin{array}{l}\text { Surface-averaged pressure difference } \\
\text { coefficient }\end{array}$ \\
\hline$D$ & Building diameter & $\Delta C_{p s l-3}$ & $\begin{array}{l}\text { Surface-averaged pressure difference } \\
\text { coefficient between Zone } 1 \text { and } 3\end{array}$ \\
\hline$d$ & Deviation in the performance degree & $\Delta C_{p s l-4}$ & $\begin{array}{l}\text { Surface-averaged pressure difference } \\
\text { coefficient between Zone } 1 \text { and } 4\end{array}$ \\
\hline$f$ & Dome rise & $\rho$ & Air density \\
\hline$f_{l}$ & Lateral middle opening rise & $\vec{a}_{i}$ & Cell face area vector \\
\hline$H$ & Dome building height & $\vec{v}_{i}$ & Air velocity vector of the cell $i$ \\
\hline$h$ & Retaining wall height & $\bar{R}_{i}$ & Surface-averaged wind speed ratio \\
\hline$i$ & Grid face index with $\mathrm{n}$ grid faces & $X m_{i}$ & Measured value \\
\hline$P$ & Wind pressure at the selected point & $X m_{\text {iave }}$ & $\begin{array}{c}\text { Average value of each point of the } \\
\text { measured value }\end{array}$ \\
\hline$P_{\infty}$ & $\begin{array}{l}\text { Static pressure at the upstream } \\
\text { reference height }\end{array}$ & $x p_{i}$ & Calculated value \\
\hline$Q$ & Ventilation rate & $X p_{\text {iave }}$ & $\begin{array}{l}\text { Average value of each point of the } \\
\text { calculated value }\end{array}$ \\
\hline$R_{i}$ & Wind speed ratio & $\gamma_{a}$ & Uniformity index \\
\hline
\end{tabular}




\section{Introduction}

It is now a fundamental requirement of environmental protection, in driving bulk terminals, power utilities and industrial plants to upgrade open stockpiles to enclosed storage facilities (Markiewicz and Christoph 2017; Speight 2013). These coal storage facilities are silos, largespan closed coal yards, air-supported membrane coal storage shed and large space circular coal storage dome (LSCCSD). Among them, the investment for LSCCSD is relatively low. It has no partition in the internal space, and the storage capacity is large. Therefore, LSCCSDs are very common in China (Aneke and Wang 2016; Dodds-Ely 2015). LSCCSD is a dome-type storage building, and constructed following the principle of natural ventilation. Due to the lack of specific ventilation design guidelines and the randomness and instability of natural ventilation, the internal environment of LSCCSD was found to be poor in the actual operating conditions (Badani-Prado et al. 2016; Dodds-Ely, 2015). The presence of toxic and harmful gases and dust not only threatens the health of workers but also is accompanied by the risk of fire and explosion (Cong et al. 2013; Onifade and Genc 2018). Effective ventilation is essential for ensuring the safety of storage facilities (NFPA120 2015; NFPA850 2015). According to NFPA120 (2015), facilities with good ventilation, which can prevent the accumulation of combustible gases or coal dust, are classified nonhazardous.

Fig. 1 shows an LSCCSD with a typical hemisphere-cylindrical structure; the diameter $D$ ranges from $100 \mathrm{~m}$ to $140 \mathrm{~m}$. The openings are mainly two types: top opening and the lateral bottom opening. There are few research studies on the ventilation performance of LSCCSD, and the relevant research theme is mainly the wind load (Liu et al. 2016; Montes and Fernandez 2001). Among other closed coal storage facilities, silos, setting inert gas protection, are usually completely closed (NFPA120 2015). Mechanical ventilation systems are usually designed for air-supported membrane coal storage shed. Zhu et al. (2017) discussed the fan selection in the 
mechanical ventilation system of the air-supported membrane coal storage shed and suggested that the dust and gas can be removed when all fans are working, so as to ensure the building safety. A large-span closed coal yard usually has sidewall openings and top openings. Zhang et al. (2017) applied the computational fluid dynamics (CFD) method to study the optimization of the airflow pattern of large-span closed coal yard, and concluded that increasing the number and reducing the spacing of sidewall openings can provide better internal airflow pattern. Only the ventilation characteristics of the large-span closed coal yard are useful to LSCCSD. Since, the sidewall openings are not set through annular $360^{\circ}$, the structure of the building is not the same, and the ventilation characteristics are different.

In order to realize effective ventilation, many scholars have carried out the optimal design (Cheng et al. 2018; Liu et al. 2014) and analyzed the influencing factors (Kindangen et al. 1997; Shetabivash 2015) of natural ventilation in conventional buildings. For design optimization of the building group, e.g., Zhou et al. (2014) used the CFD method to propose a natural ventilation optimization design strategy for residential buildings from the orientation and spacing aspects and window settings in buildings. For a single building, the roof geometry (Perén et al. 2015; van Hooff et al. 2011) and the opening modes (Chiu and Etheridge 2007; Montazeri and Montazeri 2018) are important influencing factors. Perén et al. (2015) studied the influence of roof inclination angle and opening position on the ventilation rate and found that increasing the roof inclination increases the ventilation rate. Asfour et al. (2007b) proposed that the domes improve ventilation performance in the upstream and central zones of the building. However, the influence of roof geometry on wind-induced natural ventilation has been analyzed mainly for rectangular roof or partial dome. There is a lack of research on the influence of the dome geometry of LSCCSD on natural ventilation, especially the key parameter- the rise span ratio of the dome.

Opening parameters have been paid greater attention by designers and researchers for 
cross-ventilation. Shetabivash (2015) studied the influence of the opening shape and position on ventilation and internal airflow organization, and adjusted the opening or internal separations to achieve or avoid the formation of a recirculation zone in a certain area of the room. Chiu and Etheridge (2007) studied the ventilation resistance coefficients of different opening modes and concluded that the influence of sharp-edged opening on the outdoor airflow field is lower than that of the long opening. Montazeri and Montazeri (2018) studied the influence of the relative position of the wind catcher and the outlet openings on cross ventilation and concluded that the size of the outlet openings on the leeward side has a little effect on the ventilation efficiency. Shen et al. (2016) studied the ventilation performance of a dairy building with sidewall openings, and observed that the ventilation rate depended upon the inlet and outlet sizes, while the impact of the location of openings is minute. The above studies show that there is a lack of research on the effects of parameters of annular openings, e.g., the position and size of openings, on natural ventilation performance. Increasing the area of the annular bottom opening will increase the ventilation rate, but it may cause dust emission on the windward surface of the coal pile. Another consideration is to increase the number of annular openings (the lateral middle opening in Fig. 1), which can increase the area of air inflow and achieve multi-channel air inflow.

Cao et al. (2014) reviewed the evaluation indicators of ventilation performance and put forward that the evaluation indicators should be determined according to the task of the ventilation system. Cóstola et al. (2009) pointed out that indoor environmental quality is directly affected by the ventilation rate, which depends on the wind pressure coefficient. The ventilation rate is a commonly used evaluation indicator. ASHRAE (2017) proposed that increasing ventilation is more beneficial to improve the healthy environment. The calculation of the ventilation rate requires to consider the effective area of opening (Jones et al. 2016). Norton et al. (2009) pointed out that for long sidewall openings on both sides, an airflow short circuiting occurs; thus the effectiveness of ventilation rate should be considered. Reasonable air 
distribution is a necessary guarantee for effective ventilation (Etheridge 2011). The uniformity of indoor airflow field can reduce internal vortices and improve ventilation performance (Soleimani et al. 2016). On the other hand, evaluation indicators of effective ventilation for the LSCCSD, with the particular annular opening, should be specially considered.

In order to predict natural ventilation performance, Chen (2009) reviewed different ventilation methods and identified that the CFD method is reliable and most popular. A comparison study of Asfour et al. (2007a) showed that the CFD method could better predict natural ventilation, which is in good agreement with the results of the network model. Shen et al. (2012) compared the ventilation rate by different methods for naturally ventilated livestock building, and found that the results of CFD simulation agree well with the experiments, whereas the results of the network model calculation method have large deviations. It shows that the mathematical model is more effective for the prediction of generic buildings with regular openings, while the CFD methods more accurate for building with special openings. Ramponi and Blocken (2012) investigated the impact of computational parameters by using the coupling numerical simulation method of the indoor and outdoor wind field. Following this coupling method, Perén et al. (2015) found that the RNG $k$ - $\varepsilon$ agrees well with the experimental data. Evola and Popov (2006) found that the results of RNG $k-\varepsilon$ model match better with the experimental results, and are more suitable for wind-driven natural ventilation. In order to reduce computing time in CFD, Liu et al. (2014) employed the intermediate encryption method of the grid.

Blocken (2014) reviewed validation studies of CFD simulation, and concluded that, without high quality data, the validation should be performed for simpler configurations, the flow features of which show resemblance with those expected in the case under study. CFD simulation can be validated by the scale model or wind tunnel test. The scale model test should meet the similarity criterion to ensure the accuracy of the experiment. Reynolds criterion is 
usually used in ventilation research, and higher Reynolds number than its critical Reynolds number is generally considered, so that the fluidity is similar to that of the prototype (Awbi 2003; Snyder 1981). Etheridge (2011) pointed out that when the two flows are similar, they should have the same dimensionless factor. Anderson (2017) pointed out that the wind pressure coefficient is also a similar coefficient, and it has no relation to the incoming flow velocity. Etheridge (2011) pointed out that the wind pressure coefficient is kept constant when the Reynolds number is greater than 50000. In an earlier study on dome buildings by Taylor (1991), it was found that when the Reynolds number was greater than $2 \times 10^{5}$, the pressure distribution of the dome became independent of Reynolds number. Further, Cheng and $\mathrm{Fu}(2010)$ found that even if the variation of the top and tail airflow is more complex, the difference in wind pressure distribution is very small when the Reynolds number is more than $1.58 \times 10^{5}$.

Goodfellow and Tähti (2001) mentioned that most test conditions allow only geometrical scaling. In the numerical calculation of Perén et al. (2015) and Shetabivash (2015), the calculation domain and building model were set up directly according to the experimental parameters of the wind tunnel test. Montazeri and Montazeri (2018) validated CFD by using same scale model parameters and then applied full size CFD to study further. The wind tunnel validation of Norton et al. (2009) is based on the same 1/2 scale model parameters as the wind tunnel test, and then extended to full-scale CFD for calculation and simulation. For dome building, Soleimani et al. (2016) carried out CFD validation by the wind tunnel test of Rahmatmand et al. (2014) on the external flow field, and further extended to study internal and external flow field. The calculation results of Evola and Popov (2006) showed that the ventilation deviation between $\mathrm{CFD}$ and wind tunnel test is reasonable, and the internal air distribution is well demonstrated. Therefore, CFD method, validated by available tunnel test data (Liu et al. 2016), was adopted in this study.

Construction of LSCCSDs started in late 1990s in China; research on the natural ventilation 
performance is limited and the corresponding regulations and standards are still imperfect (Markiewicz and Christoph 2017; Speight 2013). Although a large number of studies have been carried out on the optimization of natural ventilation performance of conventional buildings, there is a lack of analysis on the influence of dome geometry i.e., rise span-ratio and annular opening modes. Therefore, this study focuses on the natural ventilation performance of LSCCSDs. Combining the ventilation engineering theories (ASHRAE 2017; Awbi 2003), CFD methods (Liu et al.2014; Perén et al. 2015; Soleimani et al. 2016), scale model test (Norton et al. 2009; Shen et al. 2012), and wind tunnel test (Liu et al. 2016), we first analyze the natural ventilation airflow characteristics and establishment method of performance evaluation indicators of LSCCSD. Afterward, the influence of the rise span ratio (the ratio of dome height $f$ to dome span $D+2 w($ Fig. 1)) and the annular opening mode (including the opening position and number) on the natural ventilation performance of LSCCSD is studied. The objective is to provide basic data and a reference method for design optimization to obtain better natural ventilation in LSCCSDs.

\section{Methods}

\subsection{Analysis of ventilation characteristics and influencing factors}

According to the aerodynamic theory (Anderson 2017; ASHRAE 2017), typical flow topology around and inside an LSCCSD is shown in Fig. 2. The incoming flow firstly hits the windward surface of the LSCCSD. Then, one part of the fluid flows upward along with the dome, and then separates near the top and reattaches at the back of the flow field. Another portion of the fluid circulates in the horizontal direction on both sides of the largest crosssectional position of the LSCCSD and flows to the leeward (Liu et al. 2020), which is similar to flow around a circular cylinder. The wind flow will form a positive pressure zone on the 
windward side of the LSCCSD (red representation in Fig. 2) (Shetabivash 2015), thus forming a negative pressure zone (blue representations in Fig. 2) on the top, sides, and the leeward side. In addition, owing to reattachment in the leeward zone, a part of the wind pressure may change from negative to positive (Rahmatmand et al. 2014).

Owing to the positive and negative pressure distribution changes on the LSCCSD (Fig. 2) (Montes and Fernandez 2001; Soleimani et al. 2016), external wind flows into the LSCCSD through the annular opening at the windward side of the positive pressure zone (Fig. 3). Internal airflow forms a recirculation zone at the center of the LSCCSD (Fig. 2). Then, the air in the LSCCSD flows out through the openings at the top, sides, and leeward side of the negative pressure zone (Fig. 2 and 3) (Asfour and Gadi 2007b; Nikas et al. 2010). Therefore, pressure difference between high and low pressure zones, is the main driving force to drive the flow through the building.

The climatic factors (wind speed and wind direction), the arrangement of buildings, the shape of dome buildings, and the opening modes (position, number, size, etc.) directly affect the ventilation performance of the LSCCSD (Liu et al. 2014; Zhou et al. 2014). Since the influence of external wind field or wind directions is limited, this study focuses on the influence of (i) dome geometries (rise span ratio), and (ii) opening modes (position and number) on the natural ventilation performance of the LSCCSD. The analysis process of influencing factors is also the procedure of optimal design for natural ventilation of the LSCCSD.

\subsection{Performance evaluation indicators}

In an LSCCSD, methane and CO released from coal piles are likely to accumulate in the upper zone. At the same time, in the process of stacking and reclaiming, dust is emitted, and fine dust forms a dust cloud in the upper zone. Hence the task of natural ventilation is to eliminate the accumulation of toxic and harmful gases and prevent the formation of dust clouds by maintaining uniform and effective ventilation (ASHRAE 2019; NFPA120 2015). For these 
purposes, three evaluation indicators have been established. The first one is the wind pressure driving force indicator that is based on the wind pressure coefficient. The second one is the airflow exchange indicator based on the effective ventilation rate, and the third one is the airflow organization indicator based on wind speed ratio.

\subsubsection{Wind pressure coefficient}

In ventilation engineering, particularly in natural ventilation, the wind pressure is expressed by dimensionless wind pressure coefficient $\left(C_{p}\right)$, and the surface-averaged wind pressure coefficient $\left(C_{p s}\right)$ is commonly used to estimate the average external pressure (ASHRAE 2017; Cóstola et al. 2009). The wind pressure difference is one of the driving forces of natural ventilation. The pressure difference between the windward side and the leeward side is related to the ventilation rate (Eqs. (1), (2)) (Awbi 2003; Iqbal et al. 2014):

$$
\begin{gathered}
Q \propto\left(\left|C_{p s, \text { in }}-C_{p s, \text { out }}\right|\right)^{0.5} \\
C_{p}=\left(P-P_{\infty}\right) /\left(\rho U_{r e f}^{2} / 2\right)
\end{gathered}
$$

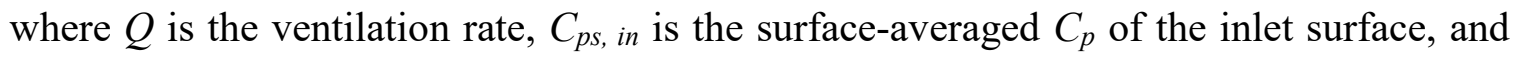
$C_{p s, \text { out }}$ is the surface-averaged $C_{p}$ of the outlet surface. $P-P_{\infty}$ is the difference between the wind pressure at the selected point and the static pressure at the upstream reference height. $U_{\text {ref }}$ is the average wind speed at the upstream reference height. $\rho$ is the air density in the standard state $\left(1.225 \mathrm{~kg} / \mathrm{m}^{3}\right)$.

\subsubsection{Ventilation rate and effective ventilation rate}

The ventilation rate, reflecting the air exchange rate (Awbi 2003), is one of the most important indicators for evaluating ventilation performance (ASHRAE 2017). In a similar situation, the openings in naturally ventilated greenhouses and livestock buildings can simultaneously allow air to enter and exit the building, e.g., when wind was blowing normal to the building, the windward sidewall opening provides $66 \%$ percentage of opening area as an inlet (Norton et al. 2009). Therefore, this study uses the CFD calculation method to obtain the 
ventilation rate $(Q)$ of the corresponding area, as represented by Eq. (3) (Norton et al. 2009):

$$
Q=\sum_{1}^{n} \vec{v}_{i} \cdot \vec{a}_{i}
$$

where $i$ is the grid face index with $\mathrm{n}$ grid faces, $\vec{v}_{i}$ is the air velocity vector of the cell $i$, and $\vec{a}_{i}$ is the cell face area vector. If the ventilation area is selected in the effective air inlet area, the corresponding ventilation rate is the effective inflow rate (Jones et al. 2016; Li and Delsante 2001). In this study, the effective air inflow rate represents the effective ventilation rate (Section 3.1), and we consider ineffective inflow rate and effective outflow rate.

\subsubsection{Wind speed ratio}

Due to the huge internal space in the LSCCSD, it is easy to have dead corners for ventilation. At the same time, it is necessary to avoid dust caused by excessive wind speed on the surface of the coal pile (ASHRAE 2019). Therefore, the airflow organization of the LSCCSD must have a certain wind speed, and it needs to maintain good airflow uniformity. In conventional applications, the air exchange rate or the ventilation rate cannot reflect the airflow uniformity, and the air age cannot reflect the wind speed. Therefore, in order to evaluate the influence of the building rise span ratio and the opening structure parameters on the indoor flow field, e.g., airflow organization, a dimensionless wind speed ratio parameter $R_{i}$ is introduced (Ramponi and Blocken 2012; Perén et al. 2015).

$$
R_{i}=\left(U / U_{r e f}\right)
$$

where $U$ is the wind velocity at the selected point.

\subsection{CFD simulation}

Owing to large space and special opening modes of dome-type storage buildings, simple empirical network models cannot be adopted for the airflow prediction under natural ventilation (Chu et al. 2009). Therefore, the CFD simulation method was adopted in this study. A commercial software program ANSYS fluent 15 (ANSYS Inc. 2013) was used to simulate the 
velocity and pressure field in and around the building.

\subsubsection{Computational domain and grid}

Owing to the complex curved structure of the LSCCSD and the internal coal pile, this study used unstructured meshing, which is widely used in building airflow modeling (Soleimani et al. 2016). The size of the calculation domain refers to the Chinese standard JGJ/T309 (2013) and Tominaga et al. (2008). The upstream and downstream lengths of the LSCCSD were selected to be $6 H$ and $12 H$, respectively. The width and height of the computational domain were selected to be $12 H$ and $4 H$, respectively (Fig. $4 a$ ). The blockage ratio was approximately $4 \%$, which was lower than the standard requirement of 5\% (ASHRAE 2017).

In order to reduce the grid number to save computing resources, the external computing domain of the LSCCSD was divided into coarse grid and fine grid zone (Fig. 4b). The fine grid zone is the double envelope zone of the LSCCSD around the building (Liu et al. 2014). Gradual encryption was performed from the middle fine grid area to the LSCCSD surface grid and the inner zone (Fig. 4c). Furthermore, the grids of the annular-opening, top opening, and the doorway zones were partially encrypted to improve the calculation accuracy (Fig. 4d). Considering the comprehensive calculation quantity and calculation accuracy, the element size was $8 \mathrm{~m}$ in the coarse grid zone, $2 \mathrm{~m}$ in the fine grid zone, and $0.5 \mathrm{~m}$ in the key zones of indoor and opening (Ramponi and Blocken 2012); the total number of grids was around $2 \times 10^{6}$.

In reference to Tominaga et al. (2008) and Perén et al. (2015), grid-independent verification was performed by the meshing method, specifically considering coarse grid, current grid, and fine grid. The numbers of grids were increased by 1.5 times, which were 1119046, 1707682, and 2560322 for coarse grid, current grid, and fine grid, respectively. A slight difference was observed in the simulated results of current grid and fine grid, whereas the difference was larger in the case of coarse grid. Therefore, current grid was used as the case to meet the requirements of a grid-independent solution (Perén et al. 2015; Ramponi and Blocken 2012). 


\subsubsection{Turbulence model and boundary-layer conditions}

Several previous studies have shown that the reliability and accuracy of the RNG $k-\varepsilon$ turbulence model are higher than the standard $k-\varepsilon$ model in the wider natural ventilation simulation (Evola and Popov 2006; Ferrucci and Brocato 2019). Thus it is more suitable for indoor and outdoor airflow simulation of large space buildings (JGJ/T309 2013). The results have been verified by experimental data (Chen 2009; Liu et al. 2014). Therefore, the RNG $k-\varepsilon$ model (Yakhot et al. 1992) was used in the CFD simulation of the airflow distribution inside and around the building.

The height of the LSCCSD is in the near-ground range of the building structure research. At the inlet of the domain the approach-flow mean wind speed profiles are imposed based on the exponential law (GB50009 2012). According to the geomorphological characteristics of the surrounding area of Beijing, the inlet wind-velocity profile is defined according to the exponential law (Eq. 5) (GB50009 2012), and the wind speed $U_{\text {ref }}$ at the reference height was obtained.

$$
U_{r e f}=U_{10} \square(Y / 10)^{0.15}
$$

where $U_{10}$ is the average wind speed $(2 \mathrm{~m} / \mathrm{s})$ in summer, which is the seasonal lowest wind speed among the four seasons, at the height of $10 \mathrm{~m}$ in Beijing; $Y$ is the reference height. Further, the speed versus height chart, represented as the user-defined function (UDF) program, was used as the boundary velocity inlet condition. A fully developed outflow boundary condition was adopted for the outlet boundary condition; the relative pressure of the environment is $0 \mathrm{~Pa}$. The ground of domain was defined as the no-slip stationary wall. The components of the internal space are simplified, and the internal coal pile was set as no-slip stationary wall.

\subsubsection{Solution method and convergence decision}

The SIMPLE algorithm was used for pressure-velocity coupling. The control and discrete formats use the second-order upwind style of the convection term in the finite volume method 
(JGJ/T309 2013). The relative iteration residuals calculated by the governing equation were less than $1 \times 10^{-3}$, and the inlet and outlet flow rate errors were less than $0.5 \%$. The calculated flow field is considered to enter a stable state when the average wind pressure value remains unchanged.

As also observed by Perén et al. (2015) and Ramponi and Blocken (2012), the simulations showed oscillatory convergence, which could be because the internal space under the dome formed a vortex that rotates in the direction of the wind.

\subsubsection{Validation by wind tunnel test}

Liu et al. (2016) conducted wind load tests on LSCCSDs at a low-speed test section of the atmospheric boundary layer wind tunnel in Shijiazhuang Tiedao University in China (Ma et al. 2015). The wind tunnel has a test section of $4.4 \times 3.0 \times 24.0 \mathrm{~m}^{3}$ (Width $\times$ Height $\times$ Length) and a wind speed range of 1.0 to $30.0 \mathrm{~m} / \mathrm{s}$. The building model (Fig. 1, without the lateral middle opening) was made from polymethyl methacrylate (PMMA) sheet at a scale of 1: 125. Corresponding to full-scale dimensions, the following parameters were taken: diameter $D=94 \mathrm{~m}$, eaves width $w=3 \mathrm{~m}$, dome span $D+2 w=100 \mathrm{~m}$, building height $H=69.3 \mathrm{~m}$, lateral bottom opening $B=3 \mathrm{~m}$, and the top opening diameter $=8 \mathrm{~m}$. In the test, the wind speed was $16 \mathrm{~m} / \mathrm{s}$, and the wind profile was also designed according to Eq. (5). The sampling frequency was 312.5 $\mathrm{Hz}$, and the number of sampling points was 6000 . For more information related to the wind tunnel experiments the reader is referred to Liu et al. (2016).

According to the building height $H$ and the test average wind speed of $16 \mathrm{~m} / \mathrm{s}$, the Reynolds number of the building is 710000 , which is much higher than the critical value of the Reynolds number entering the self-mode area of 11000 (Snyder 1981). Liu et al. (2016) provided wind pressure coefficient $C_{p}$ in wind tunnel tests. Zhou and $\mathrm{Gu}$ (2002) pointed out that a dimensionless wind velocity profile of atmospheric boundary layer is simulated in the wind tunnel, and the geometric scale ratio of the model does not affect the average wind pressure 
coefficient. Etheridge (2011) pointed out that the wind pressure coefficient of wind tunnel tests can be used for full-scale tests. Based on the CFD design method of Montazeri and Montazeri (2018), in this paper, the CFD simulation directly uses the full-scale model, and the other conditions are described in Sections 2.3.1-2.3.3. The Reynolds number is much higher than the critical Reynolds number (Cheng and Fu 2010; Taylor 1991). Therefore, in this paper, the wind pressure coefficient $C_{p}$ of the CFD simulation and the scale model test should be consistent.

In the case of the wind tunnel test and CFD simulation, the wind pressure coefficient $C_{p}$ of the dome windward $0^{\circ}$ meridian line on the XOY surface is shown in Fig. 5. In this experiment, to simplify the calculation, $U_{10}(2 \mathrm{~m} / \mathrm{s})$ was used instead of $U_{r e f}$, so that the partial $C_{p}$ value exceeds 1 .

The calculation error was determined by the error analysis method of Willmott (1981). The deviation in the performance degree $d$ ranges from 0-1 as represented by Eq. (6):

$$
d=1-\frac{\sum_{1}^{N}\left(X p_{i}-X m_{i}\right)^{2}}{\sum_{1}^{N}\left(\left|X p_{i}-X p_{\text {iave }}\right|+\left|X m_{i}-X m_{\text {iave }}\right|\right)^{2}}
$$

where $X p_{i}$ is the calculated value, $X m_{i}$ is the measured value of the wind tunnel, $X p_{\text {iave }}$ is the average value of each point of the calculated value, and $X m_{\text {iave }}$ is the average value of each point of the measured value. The calculated value is in complete agreement with the measured value when $d=1$ and the calculated value does not coincide with the measured value when $d=0$. Fig. 5 shows that $d=0.97$ as per calculated and measured values; therefore, the calculated value has high consistency with the measured value (van Hooff and Blocken 2010). Fig. 5 shows data deviation near the top opening, which is the area with the large negative pressure, causing large changes in the wind pressure on the dome. This area is prone to large wind pressure changes, with a large negative pressure zone and a convex structure. The measuring points are arranged here, which will affect the accuracy of the instrument results 
(Rahmatmand et al. 2014; Soleimani 2016).

The overall results of the wind tunnel test matched well with those of the CFD model (Shen et al. 2016), thus verifying the applicability of the CFD method (Soleimani et al. 2016; Li et al. 2016; Kubota et al. 2008). Therefore, the RNG $k-\varepsilon$ model and the related simulation conditions can be used to reflect the real wind field.

\section{Results and Discussion}

\subsection{Case calculations and basic ventilation characteristics}

This section describes the application of the CFD method to study the natural ventilation performance of the LSCCSD. A widely used, moderately sized LSCCSD with a diameter of $D$ $=120 \mathrm{~m}$ is adopted as the calculation case. The geometrical dimensions of the LSCCSD are as follows: cylindrical retaining wall height $h$ is $19 \mathrm{~m}$; dome rise $f$ is $46 \mathrm{~m}$; annular opening height $B$ is $2 \mathrm{~m}$; diameter of top opening is $16 \mathrm{~m}$, and door is $6 \mathrm{~m} \times 6 \mathrm{~m}$. The coal pile is stored in the LSCCSD, the height of the coal pile at the retaining wall is $18.5 \mathrm{~m}$, and the ridge height of the coal pile is $32 \mathrm{~m}$, which is a circular coal pile but vacant on the doorway. At the inlet of the domain the approach-flow wind speed profile is defined according to Eq. (5). The door is on the leeward side, and keeps open.

Fig. 6 and Fig. 7 depict the wind pressure distribution characteristics of the external surfaces and lateral bottom opening of LSCCSD, respectively. The calculation results are the same as those analyzed earlier (Section 2.1); the wind pressure distribution of the dome has a typical characteristic of zoning. It is assumed that the windward side of the annular lateral bottom opening is $0^{\circ}$, and the dome is divided into four zones along the longitudinal direction by $\pm 40^{\circ}, \pm 60^{\circ}$, and $\pm 120^{\circ}$. The $0^{\circ}-40^{\circ}$ red area located in the windward surface represents a strong positive pressure area (Zone 1), where preferably the opening is set to improve the ventilation rate. Furthermore, the $40^{\circ}-60^{\circ}$ yellow-green area represents a weak positive pressure 
area (Zone 2) with lower wind pressure and is prone to short flow duration; therefore, this area is not suitable to set the opening. Moreover, the $60^{\circ}-120^{\circ}$ blue area located at the top and side of the dome represents a negative pressure zone (Zone 3), where the opening is set to increase the outflow rate. The green area, which is greater than $120^{\circ}$ on the leeward surface represents the tail-flow area (Zone 4), where the opening improves the effective outflow rate. The region is symmetrical in the region of 0 to $-180^{\circ}$. The distribution characteristics of the four zones are similar to those mentioned in the literature (AIJ 2015; AS/NZS 1170. 22011).

Fig. 8 shows the CFD calculation results of the airflow streamlines through the lateral bottom opening on the windward side. The figure shows that the air entering the LSCCSD through the annular opening in the windward surface area is primarily in Zone 1. Although the airflow velocity entering the dome through the opening area of Zone 2 is greater, a short circuiting occurs.

The wind flows into the LSCCSD from the windward area of the annular opening. A part of the wind flows vertically along the upward coal pile, forming an internal vortex, and then laterally discharges from the annular opening and top opening. The other part of the wind flows horizontally along the direction of the arc of the coal pile, and is tangent to the outer wall at approximately $60^{\circ}$ around the circumference. Here, the pressure changes from positive to negative (Fig. 7), and the wind flows from inside to outside (Fig. 3). These results are consistent with the results of the ASHRAE (2017). The lateral $\pm 60^{\circ}$ is the dividing line between Zone 2 and Zone 3 , with an opening area of $40^{\circ}$ to $80^{\circ}$ and $-40^{\circ}$ to $-80^{\circ}$, which is the short circuiting area of the airflow (red circle in Fig. 8 and the pressure transition in Fig. 7), with a greater wind speed. In this case, the ineffective inflow rate of the short circuiting accounted for approximately $13 \%$ of the total inflow rate. Norton et al. (2009) found that for buildings with long side wall openings, a certain percentage of flow exited the building via short-circuiting under different wind directions. Therefore, the ventilation rate in this area was excluded from the statistical area 
of the effective ventilation area.

\subsection{Calculation conditions}

The geometric shapes of the LSCCSD affect the external pressure distribution and flow pattern. The diameter or span of the LSCCSD is first determined by site factors, so the rise span ratio is an important factor that significantly affects the wind pressure of the windward and leeward sides of the dome (Cheng et al. 2018; Chu and Chiang 2014). Simultaneously, the opening mode is another important factor affecting the ventilation and internal airflow organization. Considering the elimination of contaminants in the upper zone and avoidance of excessive wind speed on the surface of the coal pile, this paper innovatively proposes setting lateral middle opening of the dome. Therefore, this study considers the LSCCSD with a diameter of $D=120 \mathrm{~m}$ as the calculation object, and keeps the conditions same as the calculation conditions, as mentioned in Section 3.1. This section describes the investigation of the change in the rise span ratio $(f /(D+2 w))$, the number of annular openings (single-annular opening mode: only lateral bottom opening; double-annular opening mode: lateral bottom and middle openings) and the position change, affecting the natural ventilation performance of the LSCCSD. Table 1 displays the calculation conditions.

\subsection{Influence of architectural geometry on natural ventilation characteristics (Series I)}

The calculation results (Table 2) demonstrate that as the rise span ratio increases, the wind pressure on the windward side increases and the wind pressure difference between the windward side and the leeward side also increases; In other words, the wind pressure driving force increases with the height of the dome. From the surface-averaged pressure difference coefficient between Zone 1 and $3\left(\Delta C_{p s 1-3}\right)$, and Zone 1 and $4\left(\Delta C_{p s 1-4}\right)$, it was found that when the rise span ratio increased from 0.29 in Case 1 to 0.37 in Case 3, the driving force of differential pressure $\Delta C_{p s 1-3}$ and $\Delta C_{p s l-4}$ increased by $36 \%$ and $17 \%$, respectively. When the rise span ratio increased to 0.41 (Case 4$), \Delta C_{p s 1-3}$ and $\Delta C_{p s 1-4}$ increased by $45 \%$ and $22 \%$, respectively, and increased to 
0.45 (Case 5), $\Delta C_{p s 1-3}$ and $\Delta C_{p s 1-4}$ increased by $51 \%$ and $29 \%$, respectively. From the differential pressure growth rate perspective (Liu et al. 2014), the differential pressure is most effective when the rise span ratio is 0.37 .

The annular opening area of Zone $1\left(0^{\circ}\right.$ to $\pm 40^{\circ}$ in the windward side $)$ is considered as an effective inlet area (Fig. 7). The effective inflow rate is obtained by multiplying the effective air inflow area by the velocity integral over the area (Norton et al. 2009), as given by Eq. (3). Similarly, since the annular opening area of $40^{\circ}$ to $80^{\circ}$ and $-40^{\circ}$ to $-80^{\circ}$ is considered as the ineffective air inflow area, the ineffective inflow rate is obtained. The results of Fig. 9a show the ratio of effective to ineffective inflow rate, which is approximately $6.5: 1$. As the height of the dome increased, in other words, the rise span ratio increased, the effective inflow rate increased. The effective inflow rate of the rise span ratio of 0.29 (Case 1) was $160 \mathrm{~m}^{3} / \mathrm{s}$, in Case 2 increased by $9 \%$, in Case 3 increased by $28 \%$, and in Case 5 increased by $42 \%$. According to the rate of change in the effective inflow rate with the rise span ratio, the technical economy is relatively good when the rise span ratio is 0.37 (Case 3; the building height is $65 \mathrm{~m}$ ).

Since the wind from the $200^{\circ}$ region of the leeward side of the annular opening (Fig. 7) and the top opening flows through the interior of the LSCCSD, it is considered as the ideal effective outflow ventilation. The area of the annular opening corresponding to the $200^{\circ}$ area of the leeward side and the area of the top opening are considered as the effective air outlet areas. According to Eq. (3), the effective outflow area is multiplied by the velocity integral obtained over the area, and the result is shown in Fig. 9b. The comparison of the results of Fig. $9 \mathrm{~b}$ and Fig. 9a shows that the error between the effective inflow rate and the effective outflow rate is within $5 \%$, indicating the validity of the calculation.

Fig. 10 shows the contours of the wind pressure coefficient $C_{p}$ and the wind speed ratio $R_{i}$ on the XOY section (Fig. 4c), which reflects the influence of the dome shape on the wind pressure and velocity field around and inside the building (Perén et al. 2015). Fig. 10a shows 
that the windward side is a positive pressure zone, the top of the dome is a strong negative pressure zone, and the internal pressure is primarily affected by the windward wind pressure. It can be observed from the $C_{p}$ contours in Fig. 10 (left) that as the rise span ratio increases, the area of the positive pressure zone on the windward side increases; particularly, the area of the positive pressure zone at the dome of the windward surface increases. Fig. 10b shows that the flow has a weak effect on the indoor ventilation flow field, especially the central area. Corresponding to the $R_{i}$ contours in Fig. 10 (right), the driving force of the wind pressure increases with the increase in positive pressure, the length of jet flow entering the LSCCSD increases significantly, and the wind disturbance of the internal velocity field is more obvious. This is an indication that the rise span ratio is an important geometric parameter to increase wind-driven cross ventilation. Similar studies (Kindangen et al. 1997; Perén et al. 2015) found that building height has a greater impact on the indoor airflow of rectangular buildings, and increases the ventilation rate.

Furthermore, the uniformity of airflow of the XOY cross-section was evaluated based on the standard deviation of the surface-averaged wind speed ratio $\bar{R}_{i}$ and the uniformity index $\gamma_{a}$ (Eq. (7)), and $\gamma_{a} \leq 1$ (ANSYS Inc. 2013). Since suspended fine dust and light toxic and harmful gases such as $\mathrm{CH}_{4}$ and $\mathrm{CO}$ tend to accumulate in the upper part of the LSCCSD (Speight 2013), the height of the coal pile (32 m) was used as the dividing line for upper and lower zones.

$$
\gamma_{a}=1-\frac{\sum_{i=1}^{n}\left[\left(\left|R_{i}-\bar{R}_{i}\right|\right) \sqsubset a_{i}\right]}{2\left|a_{i}\right| \square \sum_{i=1}^{n} a_{i}}
$$

The calculation results in Table 3 show that as the rise span ratio increases, the wind speed ratio in the upper zone increases quickly, and the uniformity increases, resulting in improved airflow organization. However, as the rise span ratio continues to increase (to Case 5), $\bar{R}_{i}$ uniformity begins to decrease. In addition, the moderate rise span ratio reduces the standard 
deviation of $\bar{R}_{i}$. In Case 3, the standard deviation is small, and the overall uniformity is maximized.

In summary, as the rise span ratio increases, the ventilation rate increases, and the internal airflow uniformity improves, which is consistent with previous studies about rectangular building (Kindangen et al. 1997; Perén et al. 2015). By contrast, considering the growth rate on the effective ventilation rate, and internal flow field uniformity, it can be concluded that Case 3 is relatively economical and can obtain effective ventilation and indoor airflow field. Therefore, the follow-up study is based on Case 3, and the building height is set to be $65 \mathrm{~m}$.

\subsection{Influence of opening mode on natural ventilation characteristics (Series II)}

Table 4 depicts the distribution characteristics of wind pressure coefficients $C_{p s}$ in each zone under the condition of adding an annular opening in the middle of the dome. The calculation results show that compared with the data of single-annular opening (Table 2), the surface-averaged wind pressure difference coefficient $\Delta C_{p s}$ decrease, and the reason is probably that the overall wind resistance of the dome is reduced. When the position of the lateral middle opening is increased, $\Delta C_{p s 1-3}$ and $\Delta C_{p s l-4}$ value increase, but the amplitude decreases. When the ratio of the lateral middle opening center elevation to building height increases from 0.35 in Case 6 to 0.49 in Case 8 , the driving force of $\Delta C_{p s 1-3}$ and $\Delta C_{p s 1-4}$ increases by approximately $3 \%$ and $6 \%$, respectively. When the ratio is increased to 0.55 (Case 9), the $\Delta C_{p s 1-3}$ and $\Delta C_{p s 1-4}$ increase by $3 \%$ and $6 \%$, respectively. When the ratio is increased to 0.63 (Case 5), the $\Delta C_{p s}$ value of the wind pressure difference coefficient decreases. Considering the change in pressure difference and the growth rate (Liu et al. 2014), the wind pressure driving force corresponding to Case 8 and Case 9 is the most effective.

Fig. 11a shows the effective and ineffective inflow rate in the case of double-annular openings. Compare to the data in Fig. 9, the effective inflow rate of the double-annular openings can increase by $100 \%$ or more than that of the single-annular opening. For the double-annular 
opening, as the position of the lateral middle opening increases, the effective inflow rate gradually increases. For example, when the effective inflow rate increase by $7.0 \%$ in Case 8 and increases by $7.4 \%$ in Case 9, reaching the maximum in Case 9, where the position of the lateral middle opening is above the coal pile. The comparison of the results of Fig. 11b and Fig. 11a shows that the error between the effective inflow rate and effective outflow rate is still within $5 \%$.

The ratio of effective to ineffective inflow rate is reduced to $2.8: 1$, and compared with the single-annular opening, the proportion of the ineffective inflow rate is greater. The main reason for this is that, as the position height of the lateral middle opening increases, the effective inlet area of the lateral middle opening in Zone 1 decreases. On the contrary, the outflow rate at the leeward side increases owing to the enhanced negative pressure on the leeward side, as shown in Fig. 11b. The higher outflow rate on the leeward side indicates that the ventilation effect is ideal, especially in Case 9.

Fig. 12 shows the contours of $C_{p}$ and $R_{i}$ on the XOY plane in double-annular opening mode. Compared with the single-annular opening mode (Fig. 10), the wind velocity field improves and the pressure field becomes weaker after the double-annular openings are set. When the lateral middle opening position is low (Case 6 or 7), the wind flows from the inlet and then flows upward along with the coal pile, which increases the wind speed on the surface of the coal pile. The increasing wind speed increases the potential of dust emission.

It can also be observed from the graph of the $R_{i}$ that the overall flow velocity in Case 8 and Case 9 is improved, particularly in Case 9, which reduces the ventilation dead corners of the internal wind field and avoids the high wind speed along the surface of the coal pile. In Case 10, the positive pressure at the lateral middle opening is relatively low, the wind velocity field disturbance is small, and the ventilation rate is decreased.

The calculation results in Table 5 show that the $\bar{R}_{i}$ difference is not large except for Case 
10. In contrast to $\bar{R}_{i}$ in Table $3, \bar{R}_{i}$ in Table 5 demonstrates that the internal surface-average wind speed ratio increases by approximately $50 \%$, and have an obvious impact on the upper zone. The uniformity of the wind speed ratio $R_{i}$ improves as the position of the lateral middle opening increases.

Case 8 has a lower $\bar{R}_{i}$. The reason is that the lateral middle opening of Case 8 is at the same height as the ridge top of the coal pile, and the wind flow is directly blocked. In Case 9, $\bar{R}_{i}$ is relatively large, and the uniformity is also good (Fig. 12h), $\gamma_{a}$ reaches $79 \%$, resulting in improved airflow organization. Therefore, the optimal position of the lateral middle opening should be higher than the ridge top of the coal pile, and should not be set too high. Norton et al. (2009) pointed out that the wind direction affects the ventilation uniformity of rectangular long sidewall buildings. In this study, it is concluded that the opening modes of the dome-type building affects the ventilation uniformity.

The addition of an annular opening can significantly increase the effective ventilation rate. Furthermore, the effective ventilation rate and indoor airflow uniformity can be improved when the position of the lateral middle opening is increased. Shetabivash (2015) pointed out that the air inlet is close to the top of the building and has better ventilation efficiency. Perén et al. (2015) pointed out that increasing the position of the air outlet can increase the ventilation rate by up to $4 \%$, and in this paper, we found the increase of the dome-type building will be more. Case 9 could get better performance compared with other cases due to the location and reasonable annular opening.

\section{Conclusion}

Based on the established evaluation indicators of wind pressure coefficient, effective ventilation rate and wind speed ratio, the optimization design methods of natural ventilation performance of the LSCCSD are investigated deeply using CFD simulation. The optimization 
adjusted dome geometry, i.e., rise span ratio, and opening modes, which are important steps after the building determines the arrangement and size according to the site conditions. The CFD simulation results are validated with available wind tunnel experimental data. The results obtained show that:

1) The wind pressure distribution of the dome has a typical characteristic of zoning, and the classification of four zones is conducive to the study of wind pressure difference. The position of the opening, setting in the strong positive pressure zone (Zone1) on the windward side with a large wind pressure coefficient, e.g., an annular opening is set at the bottom of the dome, can increase natural ventilation potential. Effective ventilation rate should be considered to exclude the quantity of the flow left the building via "short-circuiting".

2) The increase in the rise span ratio increases the wind pressure driving force, and the effective ventilation rate increases by approximately $9 \%-42 \%$ with a single-annular opening. With double-annular openings, which are set in a strong positive pressure zone, the effective ventilation rate is twice that of the single-annular opening. Furthermore, the internal airflow organization can be improved, with a homogeneous flow field and an average wind speed ratio increase by $50 \%$, and the contaminants, accumulating in the upper zone of the LSCCSD, can be effectively removed.

3) For an LSCCSD with a diameter of $120 \mathrm{~m}$, considering the comprehensive ventilation performance and the economic investment, the optimal rise span ratio is 0.37 , and setting double-annular openings, with the optimal ratio of lateral middle opening center elevation to the building height is 0.55 .

Therefore, the presented research results provide a reference method for the design optimization of the natural ventilation performance of the LSCCSD, which can effectively improve the internal environment and reduce the safety risk for LSCCSDs. 


\section{References}

Anderson J (2017). Fundamentals of Aerodynamics (6th Edition). New York, USA: McGrawHill Education. https://www.mheducation.com/highered/product/fundamentals-aerodynamicsanderson/M9781259129919.html.

Aneke M, Wang M (2016). Energy storage technologies and real life applications - A state of the art review. Applied Energy, 179:350-377. https://doi.org/10.1016/j.apenergy.2016.06.097. ANSYS Inc. (2013). ANSYS Fluent 15.0 User's Guide, Pittsburg, U.S.A: ANSYS Inc. https://www.ansys.com/products/fluids/ansys-fluent.

AIJ (2015), RLB recommendations for loads on buildings. Tokyo Japan: Structural Standards Committee, Architectural Institute of Japan. https://www.aij.or.jp/eng/publish/index_ddonly.htm.

ASHRAE (2017). ASHRAE Handbook of Fundamentals. Atlanta, GA, USA: American Society of Heating, Refrigerating and Air-Conditioning Engineers. https://www.ashrae.org/technicalresources/ashrae-handbook/description-2017-ashrae-handbook-fundamentals.

ASHRAE (2019). ASHRAE Handbook - Heating, ventilating, and air-conditioning applications. Atlanta, GA, USA: American Society of Heating, Refrigerating and AirConditioning Engineers. https://www.ashrae.org/technical-resources/ashrae-handbook.

AS/NZS 1170. 2 (2011). Structural design actions. Part 2: Wind actions. Australian/New Zealand Standard. https://shop.standards.govt.nz/catalog/1170.2\%3A2011\%28AS\%7CNZS\%29/view. Asfour O, Gadi M (2007a). A comparison between CFD and Network models for predicting 
wind-driven ventilation in buildings. Building and Environment, 42:4079-4085. https://doi.org/10.1016/j.buildenv.2006.11.021.

Asfour O, Gadi M (2007b). Using CFD to investigate ventilation characteristics of domes as wind-inducing devices in buildings. International Journal of Green Energy Using, 571-588. https://doi.org/10.1080/15435070701583045.

Awbi H (2003). Ventilation of buildings, (2nd edition). London, UK: Spon Press. https://doi.org/10.4324/9780203634479.

Badani-Prado MA, Kecojevic V, Bogunovic D (2016). Coal quality management model for dome storage (DS-CQMM). Journal of the Southern African Institute of Mining and Metallurgy, 116:699-708. https://doi.org/10.17159/2411-9717/2016/v116n7a12.

Blocken B (2014). 50 years of computational wind engineering: past, present and future. Journal of Wind Engineering and Industrial Aerodynamics, 129:69-102. https://doi.org/10.1016/j.jweia.2014.03.008.

Cao G, Awbi H, Yao R, Fan Y, Sirén K, Kosonen R, Jensen J (2014). A review of the performance of different ventilation and air flow distribution systems in buildings. Building and Environment, 73:171-186. https://doi.org/10.1016/j.buildenv.2013.12.009.

Chen Q (2009). Ventilation performance prediction for buildings: A method overview and recent applications. Building and Environment, 44:848-858. https://doi.org/10.1016/j.buildenv.2008.05.025.

Cheng C, Fu C (2010). Characteristic of wind loads on a hemispherical dome in smooth flow and turbulent boundary layer flow. Journal of Wind Engineering and Industrial Aerodynamics, 
98:328-344. https://doi.org/10.1016/j.jweia.2009.12.002.

Cheng J, Qi D, Katal A, Wang L (Leon), Stathopoulos T (2018). Evaluating wind-driven natural ventilation potential for early building design. Journal of Wind Engineering and Industrial Aerodynamics, 182:160-169. https://doi.org/10.1016/j.jweia.2018.09.017.

Chiu Y, Etheridge D (2007). External flow effects on the discharge coefficients of two types of ventilation opening. Journal of Wind Engineering and Industrial Aerodynamics, 95:225-252. https://doi.org/10.1016/j.jweia.2006.06.013.

Chu C, Chiu Y, Chen Y, Wang Y, Chou C (2009). Turbulence effects on the discharge coefficient and mean flow rate of wind-driven cross-ventilation. Building and Environment, 44:2064-2072. https://doi.org/10.1016/j.buildenv.2009.02.012.

Chu C, Chiang B (2014). Wind-driven cross ventilation in long buildings. Building and Environment, 80:150-158. https://doi.org/10.1016/j.buildenv.2014.05.017.

Cong X, Du H, Peng S, Dai M (2013). Field measurements of shelter efficacy for installed wind fences in the open coal yard. Journal of Wind Engineering and Industrial Aerodynamics, 117:18-24. https://doi.org/10.1016/j.jweia.2013.04.004.

Cóstola D, Blocken B, Hensen J (2009). Overview of pressure coefficient data in building energy simulation and airflow network programs. Building and Environment, 44:2027-2036. https://doi.org/10.1016/j.buildenv.2009.02.006.

Dodds-Ely L (2015). Keeping bulk under wraps: enclosed storage systems and technologies in the spotlight. Dry Cargo International, 77-114. https://www.drycargomag.com/.

Etheridge D (2011). Natural ventilation of buildings: theory, measurement and design. England, 
UK: John Wiley \& Sons, Ltd. https://doi.org/10.1002/9781119951773.

Evola G, Popov V (2006). Computational analysis of wind driven natural ventilation in buildings. Energy and Buildings, 38:491-501. https://doi.org/10.1016/j.enbuild.2005.08.008.

Ferrucci M, Brocato M (2019). Parametric analysis of the wind-driven ventilation potential of buildings with rectangular layout. Building Services Engineering Research and Technology, 40:109-128. https://doi.org/10.1177/0143624418803065.

GB50009 (2012). Load code for the design of building structures. Beijing, China: China $\begin{array}{llll}\text { architecture } & \text { and } & \text { building }\end{array}$ http://book.cabplink.com/bookdetail.jsp?id=27167\&nodeid=1439. (in Chinese).

Goodfellow D, Tähti E (2001). Industrial Ventilation Design Guidebook. California, USA: Academic Press. https://doi.org/10.1016/b978-0-12-289676-7.x5000-0.

Iqbal A, Wigo H, Heiselberg P, Afshari A (2014). Effect of opening the sash of a centre-pivot roof window on wind pressure coefficients. International Journal of Ventilation, 13:273-284. https://doi.org/10.1080/14733315.2014.11684054.

JGJ/T309 (2013). The standard of the measurement and evaluation for efficiency of building ventilation. China architecture and building press, Beijing, China: China Architecture and Building Press. http://book.cabplink.com/bookdetail.jsp?id=55654\&nodeid=1439. (in Chinese).

Jones B, Cook M, Fitzgerald S, Iddon C (2016). A review of ventilation opening area terminology. Energy \& Buildings, 118:249-258. https://doi.org/10.1016/j.enbuild.2016.02.053. Kindangen J, Krauss G, Depecker P (1997). Effects of roof shapes on wind-induced air motion 
inside buildings. Building and Environment, 32:1-11. https://doi.org/10.1016/S03601323(96)00021-2.

Kubota T, Miura M, Tominaga Y, Mochida A (2008). Wind tunnel tests on the relationship between building density and pedestrian-level wind velocity: Development of guidelines for realizing acceptable wind environment in residential neighborhoods. Building and Environment, 43:1699-1708. https://doi.org/10.1016/j.buildenv.2007.10.015.

Li B, Duan R, Li J, Huang Y, Yin H, Lin C, Wei D, Shen X, Liu J, Chen Q (2016). Experimental studies of thermal environment and contaminant transport in a commercial aircraft cabin with gaspers on. Indoor Air, 26:806-819. https://doi.org/10.1111/ina.12265.

Li Y, Delsante A (2001). Natural ventilation induced by combined wind and thermal forces. Building and Environment, 36:59-71. https://doi.org/10.1016/S0360-1323(99)00070-0.

Liu Q, Lu Z, Zheng Y, Ma W, Liu X (2016). Experimental study on wind pressure distribution and wind-induced interference effects on long-span spherical structure. Jianzhu Jiegou Xuebao/Journal of Building 37:140-146. https://doi.org/10.14006/j.jzjgxb.2016.10.017. (in Chinese).

Liu S, Liu J, Yang Q, Pei J, Lai D, Cao X, Chao J, Zhou C (2014). Coupled simulation of natural ventilation and daylighting for a residential community design. Energy and Buildings, 68:686695. https://doi.org/10.1016/j.enbuild.2013.08.059.

Liu Z, Yu Z, Chen X, Cao R, Zhu F (2020). An investigation on external airflow around lowrise building with various roof types: PIV measurements and LES simulations. Building and Environment, 169:106583. https://doi.org/10.1016/j.buildenv.2019.106583. 
Ma W, Liu Q, Du X, Wei Y (2015). Effect of the Reynolds number on the aerodynamic forces and galloping instability of a cylinder with semi-elliptical cross sections. Journal of Wind Engineering and Industrial Aerodynamics, 146:71-80. https://doi.org/10.1016/j.jweia.2015.08.006.

Markiewicz A, Christoph S (2017). From stockpile to storage dome. World Coal. https://www.worldcoal.com/magazine/world-coal/october-2017/.

Montazeri H, Montazeri F (2018). CFD simulation of cross-ventilation in buildings using rooftop wind-catchers: Impact of outlet openings. Renewable Energy, 118:502-520. https://doi.org/10.1016/j.renene.2017.11.032.

Montes P, Fernandez A (2001). Behaviour of a hemispherical dome subjected to wind loading. Journal of Wind Engineering and Industrial Aerodynamics, 89:911-924. https://doi.org/10.1016/S0167-6105(01)00082-4.

NFPA120 (2015). Standard for fire prevention and control in coal mines. Massachusetts, USA: The National Fire Protection Association. https://www.nfpa.org/codes-and-standards/all-codesand-standards/list-of-codes-and-standards/ detail $?$ code $=120$.

NFPA850 (2015). Recommended practice for fire protection for Electric generating plants and high voltage direct current converter stations. Massachusetts, USA: The National Fire Protection Association. https://www.nfpa.org/codes-and-standards/all-codes-andstandards/list-of-codes-and-standards/detail?code $=850$.

Nikas K, Nikolopoulos N, Nikolopoulos A (2010). Numerical study of a naturally crossventilated building. Energy and Buildings, 42:422-434. 
https://doi.org/10.1016/j.enbuild.2009.10.010.

Norton T, Grant J, Fallon R, Sun D (2009). Assessing the ventilation effectiveness of naturally ventilated livestock buildings under wind dominated conditions using computational fluid dynamics. Biosystems Engineering, 103:78-99. https://doi.org/10.1016/j.biosystemseng.2009.02.007.

Onifade M, Genc B (2018). A review of spontaneous combustion studies-South African context. International Journal of Mining, Reclamation and Environment, 1-21. https://doi.org/10.1080/17480930.2018.1466402.

Perén J, van Hooff T, Leite B, Blocken B (2015). CFD analysis of cross-ventilation of a generic isolated building with asymmetric opening positions: Impact of roof angle and opening location. Building and Environment, 85:263-276. https://doi.org/10.1016/j.buildenv.2014.12.007.

Rahmatmand A, Yaghoubi M, Rad E, Tavakol M (2014). 3D experimental and numerical analysis of wind flow around domed-roof buildings with open and closed apertures. Building Simulation, 7:305-319. https://doi.org/10.1007/s12273-013-0157-0.

Ramponi R, Blocken B (2012). CFD simulation of cross-ventilation for a generic isolated building: Impact of computational parameters. Building and Environment, 53:34-48. https://doi.org/10.1016/j.buildenv.2012.01.004.

Shen X, Su R, Ntinas G, Zhang G (2016). Influence of sidewall openings on air change rate and airflow conditions inside and outside low-rise naturally ventilated buildings. Energy and Buildings, 130:453-464. https://doi.org/10.1016/j.enbuild.2016.08.056.

Shen X, Zhang G, Bjerg B (2012). Comparison of different methods for estimating ventilation 
rates through wind driven ventilated buildings. Energy and Buildings, 54:297-306. https://doi.org/10.1016/j.enbuild.2012.07.017.

Shetabivash H (2015). Investigation of opening position and shape on the natural cross ventilation. Energy and Buildings, 93:1-15. https://doi.org/10.1016/j.enbuild.2014.12.053.

Snyder WH (1981). Guideline for fluid modeling of atmospheric diffusion. Chicago, USA: Environmental Protection Agency. https://doi.org/EPA-600/8-81-009.

Soleimani Z, Calautit J, Hughes B (2016). Computational analysis of natural ventilation flows in geodesic dome building in hot climates. Computation, 4: 1-22. https://doi.org/10.3390/computation4030031.

Speight J (2013). Coal-Fired Power Generation Handbook. Massachusetts, USA: Scrivener Publishing - Wiley. https://doi.org/10.1002/9781118739457.

Taylor T (1991). Wind pressures on a hemispherical dome. Journal of Wind Engineering and Industrial Aerodynamics, 40:199-213. https://doi.org/10.1016/0167-6105(92)90365-H.

Tominaga Y, Mochida A, Yoshie R (2008). AIJ guidelines for practical applications of CFD to pedestrian wind environment around buildings. Journal of Wind Engineering and Industrial Aerodynamics, 96:1749-1761. https://doi.org/10.1016/j.jweia.2008.02.058.

van Hooff T, Blocken B (2010). Coupled urban wind flow and indoor natural ventilation modelling on a high-resolution grid: A case study for the Amsterdam ArenA stadium. Environmental Modelling and 25:51-65. https://doi.org/10.1016/j.envsoft.2009.07.008.

van Hooff T, Blocken B, Aanen L, Bronsema B (2011). A venturi-shaped roof for wind-induced 
natural ventilation of buildings: Wind tunnel and CFD evaluation of different design configurations. Building and Environment, 46:1797-1807. https://doi.org/10.1016/j.buildenv.2011.02.009.

Guan Y, Li A, Zhang Y, Jiang C, Wang Q (2016). Experimental and numerical investigation on the distribution characteristics of wind pressure coefficient of airflow around enclosed and openwindow buildings. Building Simulation, 9:551-568. https://doi.org/10.1007/s12273-016-02836.

Willmott C (1981). On the validation of models. Physical Geography, 2:184-194. https://doi.org/10.1080/02723646.1981.10642213.

Yakhot V, Orszag S, Thangam S, Gatski T, Speziale C (1992). Development of turbulence models for shear flows by a double expansion technique. Physics of Fluids A, 4:1510-1520. https://doi.org/10.1063/1.858424.

Zhang W, Li A, Shen D (2017). Numerical simulation of natural ventilation and scheme determination for a closed large-span industrial building. Building Energy and Environment, 136:90-94. https://doi.org/10.3969/j.issn.1003-0344.2017.06.023. (in Chinese).

Zhou C, Wang Z, Chen Q, Jiang Y, Pei J (2014). Design optimization and field demonstration of natural ventilation for high-rise residential buildings. Energy and Buildings, 82:457-465. https://doi.org/10.1016/j.enbuild.2014.06.036.

Zhou X, Gu M (2002). Test study of wind pressure coefficient on long-span roof. Journal of Tongji University, 30:1423-1428. https://doi.org/10.3321/j.issn:0253-374X.2002.12.003. (in Chinese). 
Zhu Y, Zhao B, Wang J, Su R, Wang Q (2017). Ventilation system design for air supported structure of coal storage. Journal of HV\&AC, 47:89-92. http://kns.cnki.net/KCMS/detail/detail.aspx?FileName=NTKT201705016\&DbName=CJFQ20 20. (in Chinese). 


\section{Tables}

\section{Table 1}

Calculation conditions of the cases for rise span ratio and opening modes effect.

\begin{tabular}{ccccc}
\hline Cases & & $\begin{array}{c}\text { Rise span } \\
\text { ratio } \\
f l(D+2 w)\end{array}$ & $\begin{array}{c}\text { Lateral bottom opening } \\
\text { center elevation / Building } \\
\text { height } \\
(h+1 / 2 B) / H\end{array}$ & $\begin{array}{c}\text { Lateral middle opening } \\
\text { center elevation / Building } \\
\text { height } \\
\left(h+f_{1}+1 / 2 B\right) / H\end{array}$ \\
\hline Series I: & Case 1 & 0.29 & 0.36 & - \\
Rise span & Case 2 & 0.33 & 0.33 & - \\
ratio & Case 3 & 0.37 & 0.31 & - \\
changes & Case 4 & 0.41 & 0.28 & - \\
& Case 5 & 0.45 & 0.26 & 0.35 \\
Series II: & Case 7 & 0.37 & 0.31 & 0.40 \\
Opening & Case 8 & 0.37 & 0.31 & 0.49 \\
modes & Case 9 & 0.37 & 0.31 & 0.55 \\
& Case 10 & 0.37 & 0.31 & 0.63 \\
\hline
\end{tabular}

\section{Table 2}

Surface-averaged pressure coefficient $C_{p s}$ and pressure difference coefficient $\Delta C_{p s}$ of the dome zones for different $f /(D+2 w)$.

\begin{tabular}{lcccccc}
\hline \multirow{2}{*}{ Case } & \multicolumn{5}{c}{ Surface-averaged pressure coefficient $C_{p s}$} & \multicolumn{2}{c}{ Surface-averaged pressure difference coefficient $\Delta C_{p s}$} \\
\cline { 2 - 7 } & Zone 1 & Zone 2 & Zone 3 & Zone 4 & $\Delta C_{p s l-3}$ & $\Delta C_{p s l-4}$ \\
\hline Case 1 & 0.47 & 0.14 & -0.09 & -0.06 & 0.56 & 0.52 \\
Case 2 & 0.48 & 0.17 & -0.12 & -0.07 & 0.60 & 0.55 \\
Case 3 & 0.52 & 0.15 & -0.24 & -0.09 & 0.76 & 0.61 \\
Case 4 & 0.54 & 0.12 & -0.27 & -0.10 & 0.81 & 0.64 \\
Case 5 & 0.57 & 0.11 & -0.27 & -0.10 & 0.84 & 0.68 \\
\hline
\end{tabular}


Table 3

Dimensionless surface-averaged velocity magnitude $\bar{R}_{i}$ on the XOY cross-section of internal LSCCSD.

\begin{tabular}{|c|c|c|c|c|c|}
\hline \multirow{2}{*}{ Cases } & \multicolumn{3}{|c|}{ Surface-averaged velocity magnitude $\bar{R}_{i}$} & \multirow{2}{*}{$\begin{array}{l}\text { Standard } \\
\text { Deviation }\end{array}$} & \multirow{2}{*}{$\begin{array}{c}\text { Uniformity index } \\
\gamma_{a}\end{array}$} \\
\hline & Entire zone & Upper zone & Lower zone & & \\
\hline Case 1 & 0.11 & 0.10 & 0.11 & 0.28 & 0.77 \\
\hline Case 2 & 0.12 & 0.11 & 0.12 & 0.24 & 0.79 \\
\hline Case 3 & 0.13 & 0.13 & 0.13 & 0.25 & 0.80 \\
\hline Case 4 & 0.13 & 0.14 & 0.13 & 0.27 & 0.80 \\
\hline Case 5 & 0.14 & 0.14 & 0.14 & 0.26 & 0.78 \\
\hline
\end{tabular}

Table 4

Surface-averaged pressure coefficient $C_{p s}$ and pressure difference coefficient $\Delta C_{p s}$ of dome zones for different $\left(\left(h+f_{1}+1 / 2 B\right) / H\right)$.

\begin{tabular}{|c|c|c|c|c|c|c|}
\hline \multirow[t]{2}{*}{ Cases } & \multicolumn{4}{|c|}{ Surface-averaged pressure coefficient $C_{p s}$} & \multicolumn{2}{|c|}{ Surface-averaged pressure difference coefficient $\Delta C_{p}$} \\
\hline & Zone 1 & Zone 2 & Zone 3 & Zone 4 & $\Delta C_{p s l-3}$ & $\Delta C_{p s l-4}$ \\
\hline Case 6 & 0.40 & 0.03 & -0.24 & -0.08 & 0.64 & 0.48 \\
\hline Case 7 & 0.41 & 0.04 & -0.24 & -0.07 & 0.65 & 0.48 \\
\hline Case 8 & 0.44 & 0.07 & -0.22 & -0.08 & 0.66 & 0.51 \\
\hline Case 9 & 0.44 & 0.08 & -0.22 & -0.06 & 0.66 & 0.51 \\
\hline Case 10 & 0.45 & 0.14 & -0.12 & -0.07 & 0.58 & 0.52 \\
\hline
\end{tabular}

Table 5

Dimensionless surface-averaged velocity magnitude $\bar{R}_{i}$ on the XOY cross-section of internal LSCCSD.

\begin{tabular}{|c|c|c|c|c|c|}
\hline \multirow{2}{*}{ Cases } & \multicolumn{3}{|c|}{ Surface-averaged velocity magnitude $\bar{R}_{i}$} & \multirow{2}{*}{$\begin{array}{l}\text { Standard } \\
\text { Deviation }\end{array}$} & \multirow{2}{*}{$\begin{array}{l}\text { uniformity } \\
\text { index } \gamma_{a}\end{array}$} \\
\hline & Entire zone & Upper zone & Lower zone & & \\
\hline Case 6 & 0.19 & 0.19 & 0.18 & 0.35 & 0.75 \\
\hline Case 7 & 0.18 & 0.19 & 0.18 & 0.31 & 0.77 \\
\hline Case 8 & 0.17 & 0.17 & 0.15 & 0.33 & 0.77 \\
\hline Case 9 & 0.18 & 0.19 & 0.18 & 0.33 & 0.79 \\
\hline Case 10 & 0.14 & 0.16 & 0.12 & 0.36 & 0.79 \\
\hline
\end{tabular}




\section{Figures and figure captions}

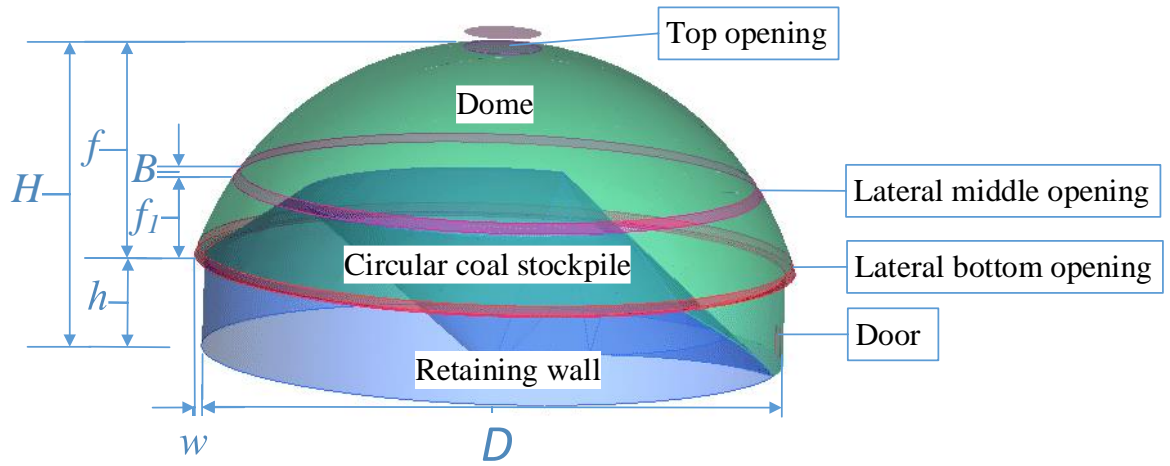

Fig. 1. Schematic of the LSCCSD ( $H$ : dome building height; $h$ : retaining wall height; $B$ : opening height; $f$ : dome rise; $f_{1}$ : lateral middle opening rise; $D$ : building diameter; $w$ : dome cornice width).

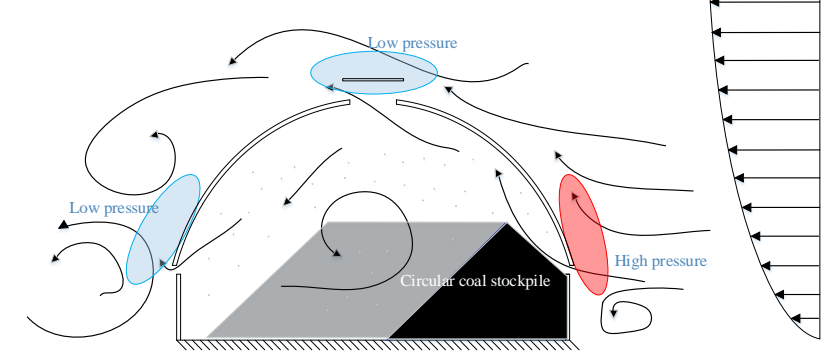

Fig. 2. Schematic diagram illustrating natural ventilation principle of LSCCSD with single-annular and top openings.

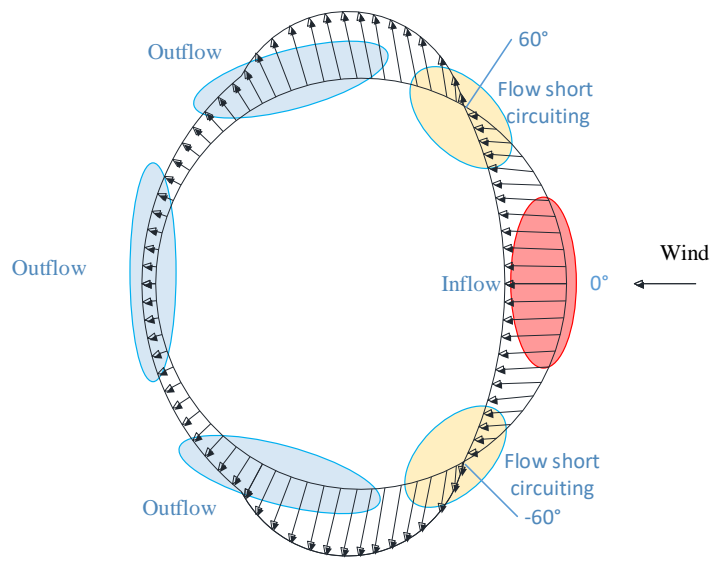

Fig. 3. Schematic diagram illustrating the air stream through the lateral bottom opening. 
(a)

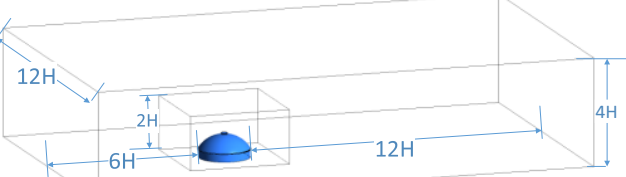

(b)

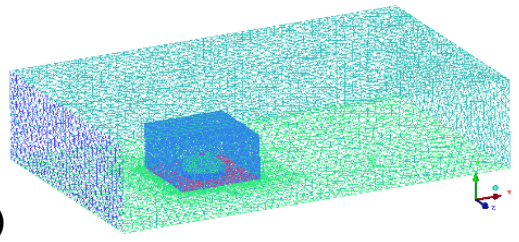

(c)

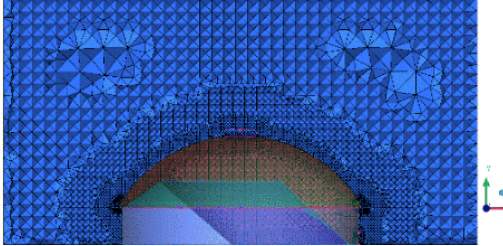

(d)

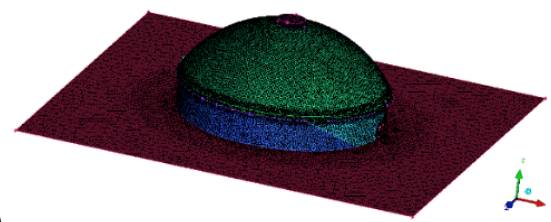

Fig. 4. Calculation domain and grid. (a) Computational domain, (b) Computational domain grid and intermediate encryption, (c) XOY cross section grid, (d) LSCCSD grid.

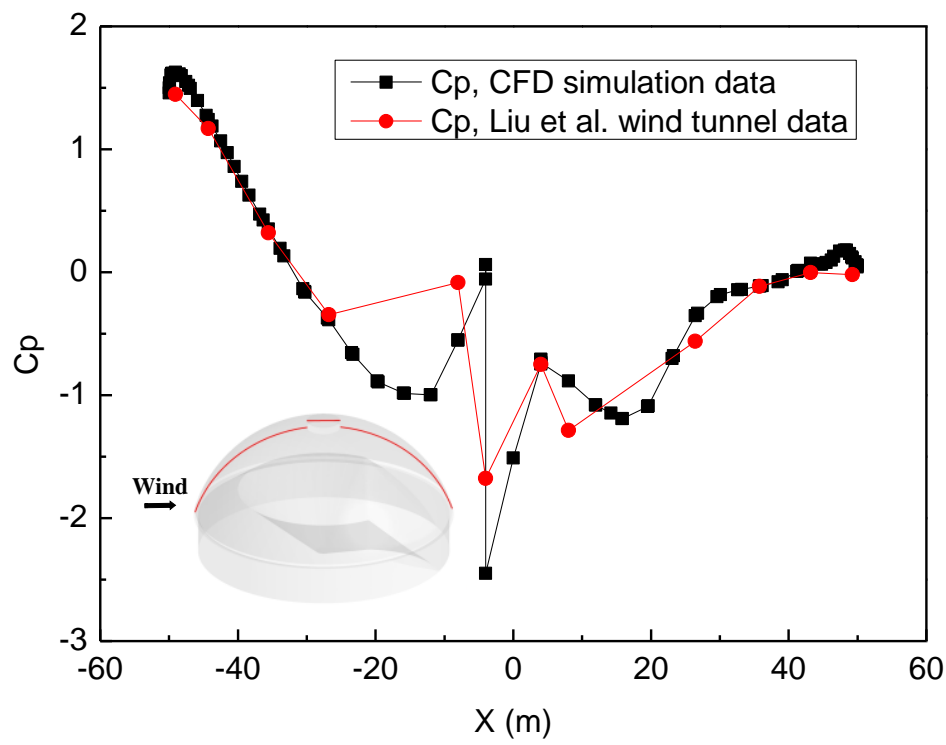

Fig. 5. Comparison of wind pressure coefficient $C_{p}$ along windward $0^{\circ}$ meridian line by simulated and experimental results. 


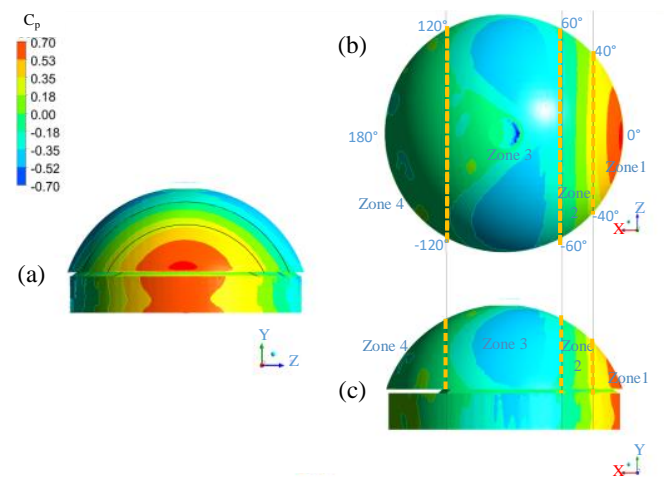

Fig. 6. Wind pressure distribution and four zones of LSCCSD. (a) front view, (b) top view, (c) side view.

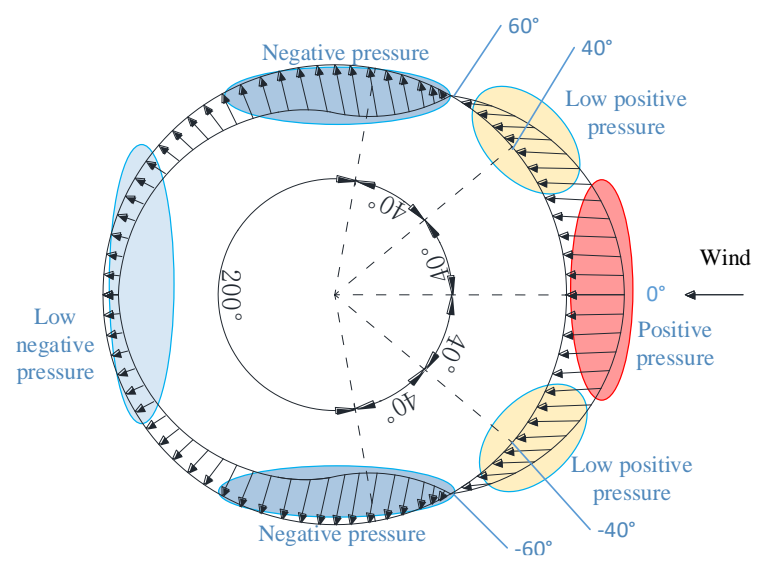

Fig. 7. Wind pressure distribution on the lateral bottom opening of the dome.
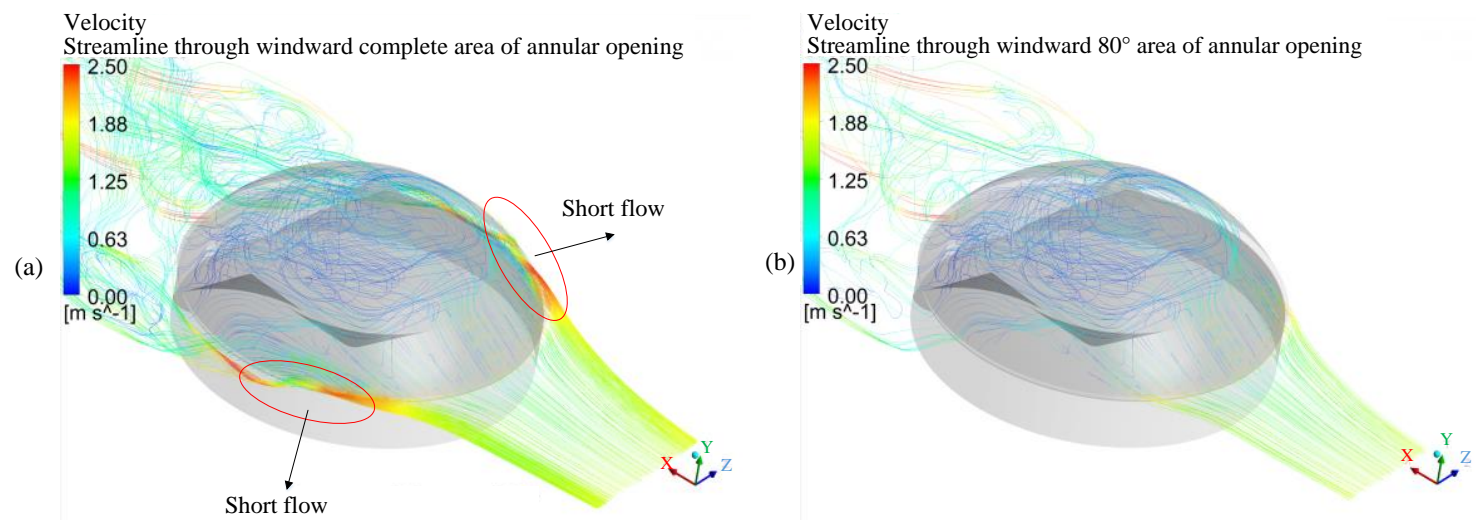

Fig. 8. Streamlines through the lateral bottom opening on the windward side. (a) streamlines through the complete opening area, (b) streamlines through windward $0^{\circ}$ to $\pm 40^{\circ}$ effective inlet area (Zone1). 


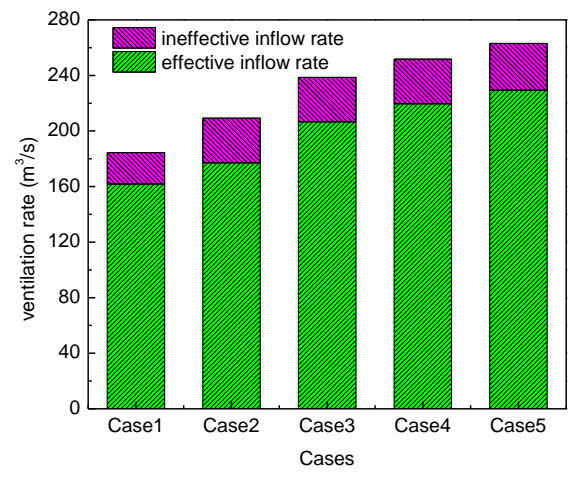

(a)

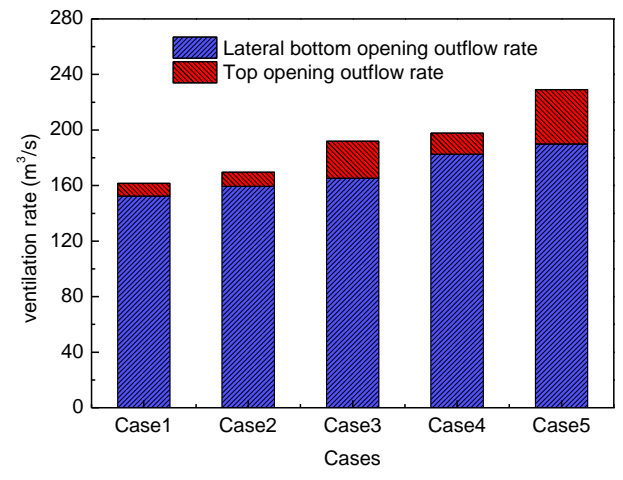

(b)

Fig. 9. Comparison of inflow rate and outflow rate in Case 1 to Case 5. (a) effective inflow rate and ineffective inflow rate (b) effective outflow rate.

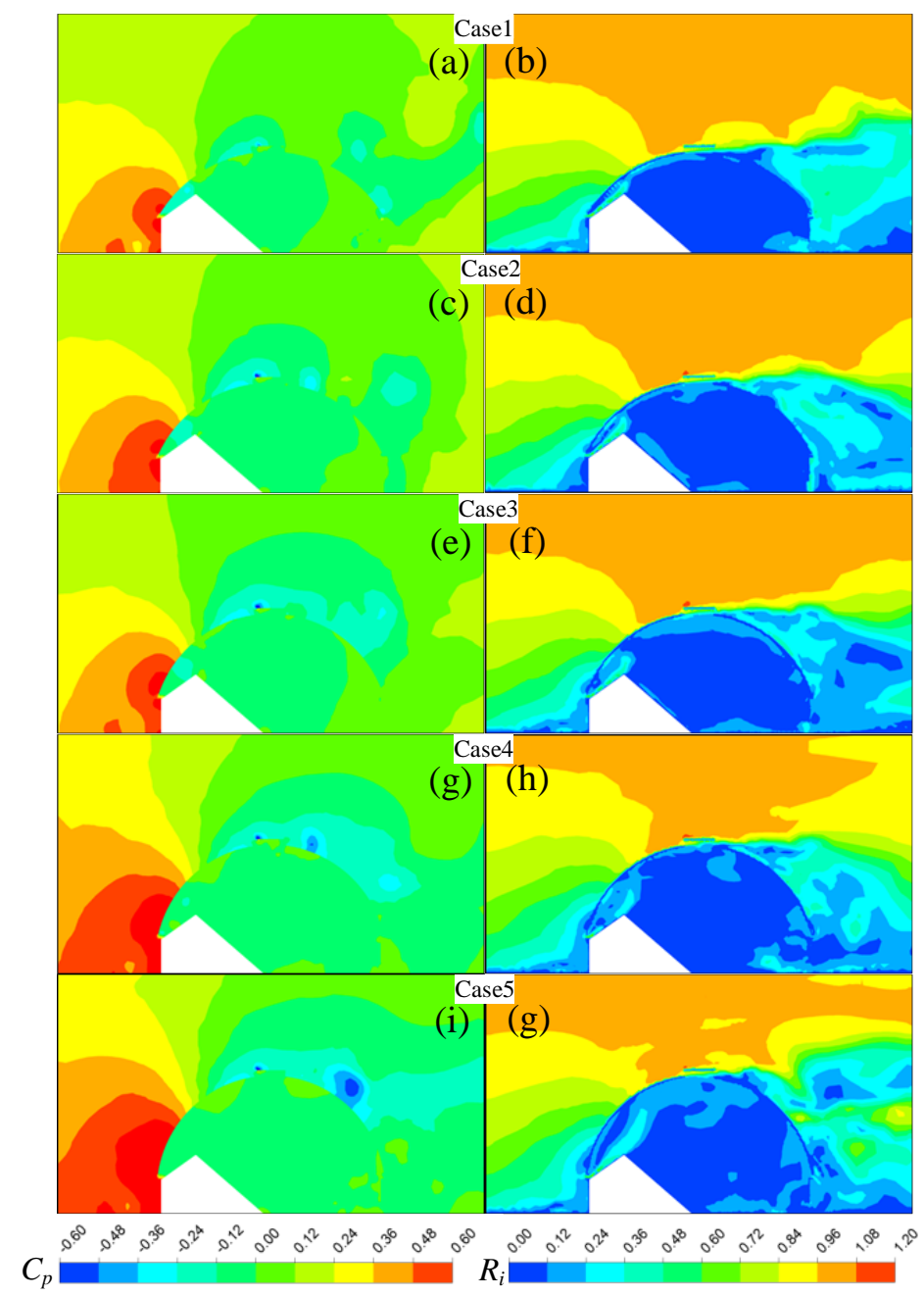

Fig. 10. Contours of Case 1 to Case 5 in the vertical center XOY plane (white region representing the coal). (a, c, e, g, i) Contours of pressure coefficient $C_{p}$. (b, d, f, h, j) Contours 
of dimensionless velocity magnitude $R_{i}$.

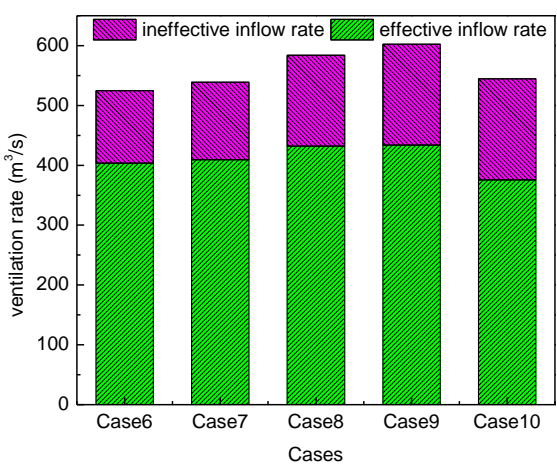

(a)

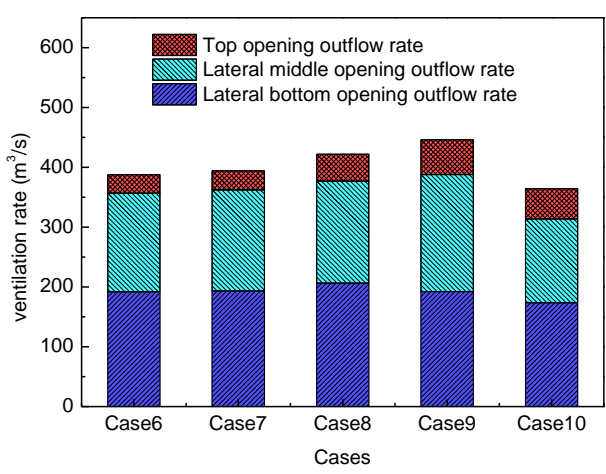

(b)

Fig. 11. Comparison of inflow rate and outflow rate of Case 6 to Case 10. (a) effective inflow rate and ineffective inflow rate (b) effective outflow rate.

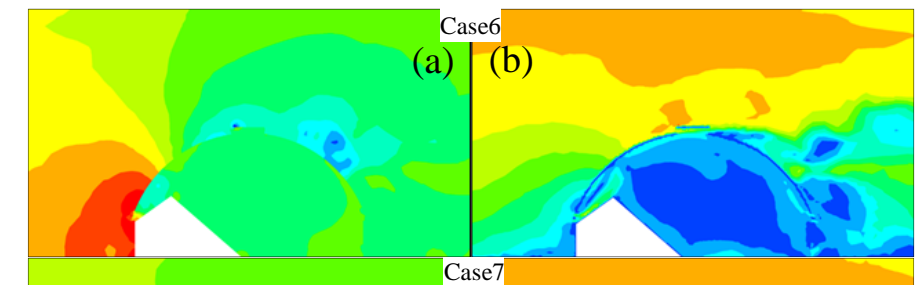

(c) (d)

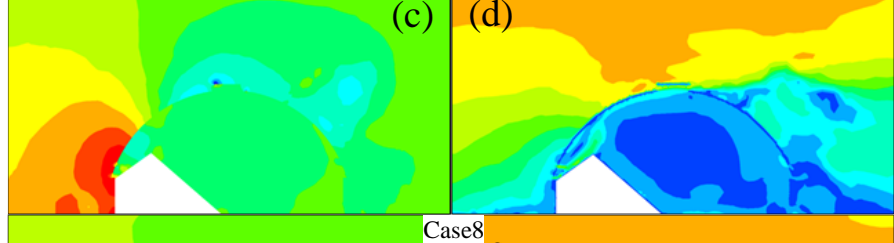

(e) (f)
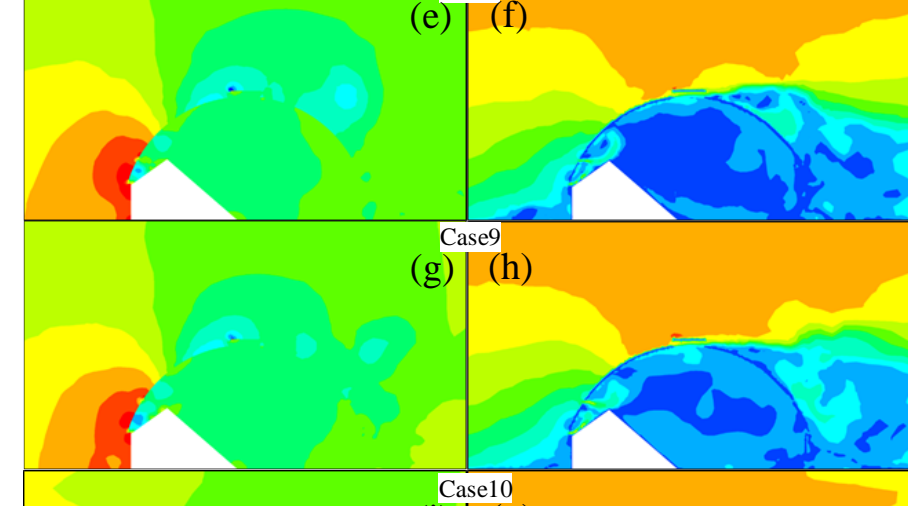

(i) $(\mathrm{g})$

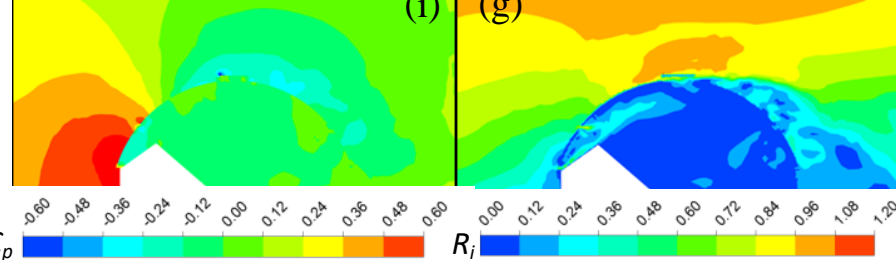

Fig. 12. Contours of Case 6 to Case 10 in the vertical center XOY plane (white region representing the coal). (a, c, e, g, i) Contours of pressure coefficient $C_{p} .(\mathrm{b}, \mathrm{d}, \mathrm{f}, \mathrm{h}, \mathrm{j})$ Contours 
of non-dimensional velocity magnitude $R_{i}$. 